Bangladesh J. Bot. 48(1): 129-138, 2019 (March)

\title{
EFFECTS OF GENOTYPE AND GROWING SUBSTRATE ON BIO-EFFICIENCY OF GOURMET AND MEDICINAL MUSHROOM, LENTINULA EDODES (BERK.) PEGLER
}

\author{
Sudheer Kumar Annepu*, Sharma VP, Anupam Barh, Satish Kumar, \\ Mahantesh Shirur and Shwet Kamal
}

\author{
Indian Council of Agricultural Research-Directorate of Mushroom Research, \\ Chambaghat, Solan, Himachal Pradesh, India
}

Keywords: Shiitake, Bio-efficiency, Substrate composition, Lignocellulosic residues, Agro-wastes

\begin{abstract}
The preference of a particular strain to a specific substrate in shiitake mushroom was investigated. The effect of different genotypes (DMRO-34, DMRO-23, DMRO-327 and DMRO-388s), substrates (sawdust and wheat straw) and their interactions were found highly significant for yield and yield attributing factors. Strain DMRO-388s recorded the highest bio-efficiency (85.63\%) on saw dust (SD) and the strain DMRO-327 with $53.02 \%$ on wheat straw (WS). The mycelial colonization was rapid on SD, while the sporophore formation was found earlier on WS. Breakdown of phenolic compounds in the substrate was found much higher in WS particularly with strain DMRO-327. Ability of the strains to degrade lignin content was found higher by the strain DMRO-388s (58.78\%) in SD. Hemicellulose concentration decreased in both the substrates with each passing growth stage and it was found much rapid with DMRO-388s after spawn run stage. Of the substrates used, SD gave higher yield over the WS. But the earliness of fruiting on WS can economize the cost of shiitake cultivation as it is cheap and abundantly available.
\end{abstract}

\section{Introduction}

Shiitake mushroom, Lentinula edodes (Berk.) Pegler, cultivation is gaining popularity in recent years, owing to new-found demand among the urban consumers. The bioactive compound, lentinan extracted from the fruit bodies of shiitake is reported to have several anti-tumour properties and found with therapeutic applications in various cancer treatments (Bisen et al. 2010). The total production of shiitake has registered many folds increase in the last two decades and at present it is the highest contributor to the world mushroom production (Royse et al. 2017). Cultivation of shiitake on natural wood logs is a well-established practice in countries like China, Taiwan, Japan, Korea, etc. where the climate is congenial and wood availability is not a problem. However, intensive shiitake cultivation using wood shavings or finely powdered saw dust (SD) obtained from the broad-leaved trees has revolutionized its production. The wood shavings and SD are made into synthetic wood logs to cultivate the shiitake mushroom. This artificial log cultivation technique scores over the natural log method with respect to production time and efficiency. China has made rapid progress in shiitake production led by growers' innovations in cultivation techniques to reduce the input costs (Shen et al. 2004). In India, commercial cultivation of shiitake mushroom is still at a primitive stage (Sharma et al. 2017) and needs serious attention to promote it as an economic activity.

In India and other developing countries, quality wood residues are scarce and the demand for them is expected to rise for their multiple uses. As a result, research efforts are concentrated on utilization of alternate agro-residues as production substrates for growing shiitake. Mata et al. (2001), Gaitan-Hernandez et al. (2006), Philippoussis et al. (2007) studied the possibility of

\footnotetext{
*Author for correspondence: <sudheerannepu@gmail.com>.
} 
growing shiitake on straw-based substrates. To promote the shiitake cultivation on nonconventional agro-residues like wheat straw (WS), it demands more information on comparative productivity of superior strains on WS and SD. It is perceived that, during the different phases of fungal growth, the substrate might have undergone various physical and chemical changes subsequently leading to formation of mushrooms (Gaitan-Hernandez et al. 2011). Understanding the potentiality of specific genotype on substrate utilization pattern and subsequent mushroom production provides helpful information on further selection of suitable substrate composition specific to genotype. Hence, the present study examines the effect of genotype and its interaction with the substrate on compositional variations of the substrate material and its possible relationship with the yield of shiitake.

\section{Materials and Methods}

Initial screening trials were conducted at Indian Council for Agricultural Research (ICAR)Directorate of Mushroom Research (DMR), Solan, Himachal Pradesh, India with 32 genotypes on four different substrates. Among them, 19 strains produced fruiting bodies on SD and 9 strains were found with fruiting ability on WS. No sporophore formation was observed on paddy straw and coir pith. For effective utilization of available cropping room space, four high yielding strains viz., DMRO-23, DMRO-34, DMRO-327 and DMRO-388s registered with the fungal culture collection of the ICAR-DMR, Solan (Himachal Pradesh), India were used in the present study.

SD of Toona sinensis [(A. Juss.) M. Roem] and chopped WS of $4-6 \mathrm{~cm}$ length were used as the basic ingredients for substrate preparation. Supplementation was done with $19 \%$ wheat bran and $1 \% \mathrm{CaCO}_{3}$ on dry weight basis for both the substrates. The SD and WS were soaked overnight for wetting and drain out the excess water on the next day. The moisture content was recorded at $62.4 \%$ in SD and $65.1 \%$ in WS. Wheat bran and $\mathrm{CaCO}_{3}$ were mixed thoroughly with the wetted substrate and $1.0 \mathrm{~kg}$ material was filled in heat resistant polypropylene bags of 180-micron gauge thickness. The filled bags were closed by heat resistant polypropylene necks plugged with nonabsorbent cotton to facilitate gaseous exchange. These bags were then sterilized at $121^{\circ} \mathrm{C}$ and 15 p.s.i pressure for $120 \mathrm{~min}$. Later the substrate was cooled down to the room temperature and surface spawned with identified strains prepared on wheat grains @ 5\% on wet weight basis.

Cropping trials were conducted under controlled conditions suitable for growing shiitake on bag logs. The temperature was maintained at $25 \pm 2$ and $20 \pm 2^{\circ} \mathrm{C}$ for incubation and fruiting, respectively (Donoghue and Denison 1995). After spawning, the bag logs were shifted to a closed dark room for incubation. No specific measures were taken to control the relative humidity (R.H.), $\mathrm{CO}_{2}$ and light. However, the random observations showed that the R.H. during the incubation period ranged between 45 and $60 \%$ and the $\mathrm{CO}_{2}$ level was 1600 - 2000 ppm. For fruiting, the R.H. was maintained at $80 \pm 5 \%$ and illumination was provided with fluorescent light for four hrs a day (Shen et al. 2008). The level of $\mathrm{CO}_{2}$ was maintained in a range of $800-1000$ ppm by air recirculation. The bags were observed until the appearance of mycelia bumps which is an indication for completion of the incubation phase. Fruiting was induced by soaking the bag logs in ice-cold water $\left(4-6^{\circ} \mathrm{C}\right)$ for $15 \mathrm{~min}$ after peeling the polypropylene bags. Cold water soaking was repeated for second and third flushes also. In all the flushes, matured fruit bodies were harvested before unveiling the cap margin. Observations were recorded on days for completion of spawn run, days for first fruiting, yield distribution among different flushes, total yield, biological efficiency (BE) (total fresh yield per dry weight of the substrate) and production period (time from spawning to the last harvest of fruit bodies). Average fruit body weight (g) and pileus thickness $(\mathrm{cm})$ were taken as quality parameters. 
To analyze the variations in the lignocellulosic composition of the substrate, the samples were drawn at substrate preparation (as control), after completion of spawn run (indicated by $100 \%$ substrate colonization), primordial formation stage (appearance of mycelia bumps) and after completion of cropping. The representative samples were analysed for $\mathrm{pH}$, moisture (\%) and total phenols by Folin Ciocalteu method (Blainski et al. 2013) using fresh samples and lignin (\%), cellulose $(\%)$ and hemicellulose (\%) concentrations in oven-dried samples as described by Goering and Van Soest (1970).

The experiment was conducted in a completely randomized factorial design with three replications. For each replication nine bag logs were prepared, and data represented an average of nine bags for each replication. Two consecutive trials were conducted, and the data presented is the average of two trials. An analysis of variance was conducted for all variables and a least squares analysis as described by Cochran and Cox (1957) to examine factor interactions using R-Studio open source software (version 1.0.136).

\section{Results and Discussion}

ANOVA of factorial design showed that, the genotypes differed significantly for days for spawn run, days for first harvest, total yield, yield distribution among different flushes, individual fruit body weight and pileus thickness (Table 1). The two substrates (SD and WS) have significant effects on all the characters under study. The interaction effect of substrate and genotypes is also found significant except for days for completion of spawn run. This suggests the genotype preference for the substrate. Completion of spawn run indicated by $100 \%$ mycelial colonization was found quicker in SD compared to WS; whereas, mean days to primordial formation was found earlier in WS.

Table 1. Probabilities (p) greater than Fisher's (F) test from analysis of variance.

\begin{tabular}{lcccccccc}
\hline $\begin{array}{l}\text { Source of } \\
\text { variation } \\
\text { due to error }\end{array}$ & Dof & $\begin{array}{l}\text { Days for } \\
\text { complete } \\
\text { spawn run }\end{array}$ & $\begin{array}{l}\text { Days for } \\
\text { first } \\
\text { harvest }\end{array}$ & $\begin{array}{l}\text { Total } \\
\text { yield }\end{array}$ & BE & PP & $\begin{array}{l}\text { Average } \\
\text { fruit } \\
\text { body wt. }\end{array}$ & $\begin{array}{l}\text { Pileus } \\
\text { thickness }\end{array}$ \\
\hline Genotype & 3 & 0.00000 & 0.00000 & 0.00000 & 0.00000 & 0.00000 & 0.00918 & 0.00000 \\
Substrate & 1 & 0.00017 & 0.00000 & 0.00000 & 0.00000 & 0.00000 & 0.00055 & 0.00000 \\
Genotype $\times$ & 3 & 0.09997 & 0.00000 & 0.00001 & 0.00001 & 0.00000 & 0.00003 & 0.00000 \\
substrate & & & & & & & \\
\hline
\end{tabular}

Probability values less than 0.05 were considered significant.

Strain DMRO-388s took 22.33 and 24.33 days for complete spawn run on SD and WS, respectively. For fruiting DMRO-388s took 53 days on WS and 59.33 days on SD. Even though, the spawn run was completed two days earlier in SD, the fruiting was found 6.33 days earlier in WS. Primordial formation on WS was found earlier than SD in several other experiments (Crestini et al. 1998, Philippoussis et al. 2007). Owing to its requirement for the longer pre-incubation period, the strain with quick fruiting ability has higher economic significance in the commercial production of shiitake mushroom (Sharma et al. 2018). In strain DMRO-23 no sign of fruiting was observed on WS even after complete mycelial colonization. On SD, the first flush was harvested after 102.33 days which was highest among all the combinations. The pileus thickness $(21.67 \mathrm{~mm})$ and individual fruit body weight ( $36.58 \mathrm{~g})$ were found highest in DMRO-23. The results can be inferred that, longer pre-incubation period has led to the production of good quality basidiospores. 
The yield of different genotypes varied greatly on both the substrates (Table 2). The two most productive strains on SD were DMRO-388s $(85.63 \% \mathrm{BE})$ followed by DMRO-34 (62.70\% BE). On WS, DMRO-327 recorded highest BE of $53.02 \%$ followed by $41.70 \%$ BE by DMRO-388s. Substrate mean showed $49.62 \%$ higher BE in SD than WS. The results are in contrast with the findings of Philippoussis et al. (2007) where higher yield levels were reported on WS than SD of oak wood. The data registered on yield distribution provide an insight into the production pattern of different high yielding strains (Fig. 1). The total yield obtained from the strain DMRO-388s was distributed among three flushes uniformly. SD supported the production of heavier mushrooms for DMRO-23 (36.58 g), DMRO-34 (25.63 g) and DMRO-388s (23.23 g). DMRO$327(32.25 \mathrm{~g})$ produced heavy mushrooms with pileus thickness of $16.33 \mathrm{~mm}$ on WS which is significantly higher than other strains.

On WS, total yield produced by strain DMRO-34, DMRO-327 and DMRO-388s harvested from in single flush itself (Fig. 1.). The bag logs of WS did not respond to the further cold water soaking treatments and no successive flushes were obtained. These findings are in contrast with the observations made by Philippoussis et al. (2003) where equal yield distribution was reported in different flushes on WS. Despite the lower yield of individual genotypes on WS over SD, the use of WS as basic substrate comes as an advantage in the commercial production of shiitake as it is cheap and available in plenty.

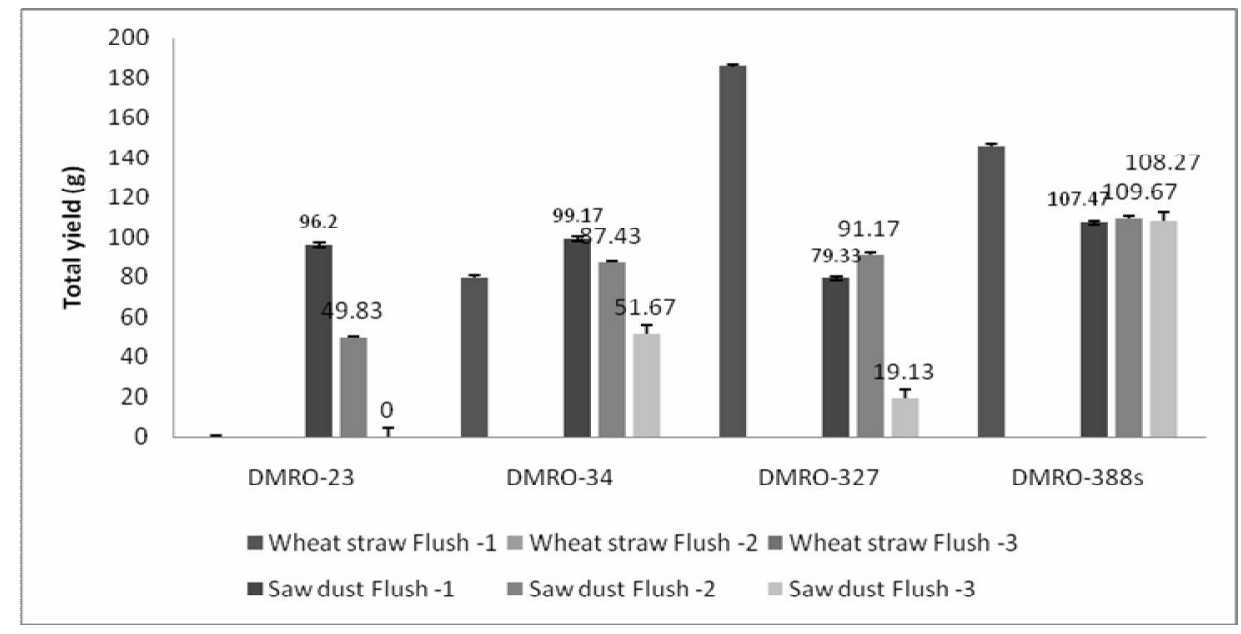

Fig. 1. Yield distribution of different genotypes among three flushes on WS and SD.

Unlike SD, which gives fruiting in three successive flushes spread over 30 - 40 days period, the wheat straw logs gave the maximum yield in a single break. This factor can be explored further as it will give way to make use of time and growing space. Since time has an opportunity cost, the production period is an important criterion in speciality mushroom production. Besides it saves electricity and fuel charges needed to maintain the cropping room conditions during the fruiting period. Among different strains produced fruiting on WS, lesser production period was recorded in WS (65.67 days) against 132.83 in SD. The production period was maximum for strain DMRO327 (140.67 days) followed by DMRO-34 (138.67 days) on SD. Strain DMRO-388s recorded a 70 days production period on WS which is lowest among all the substrate and strain combinations (Table 2). 


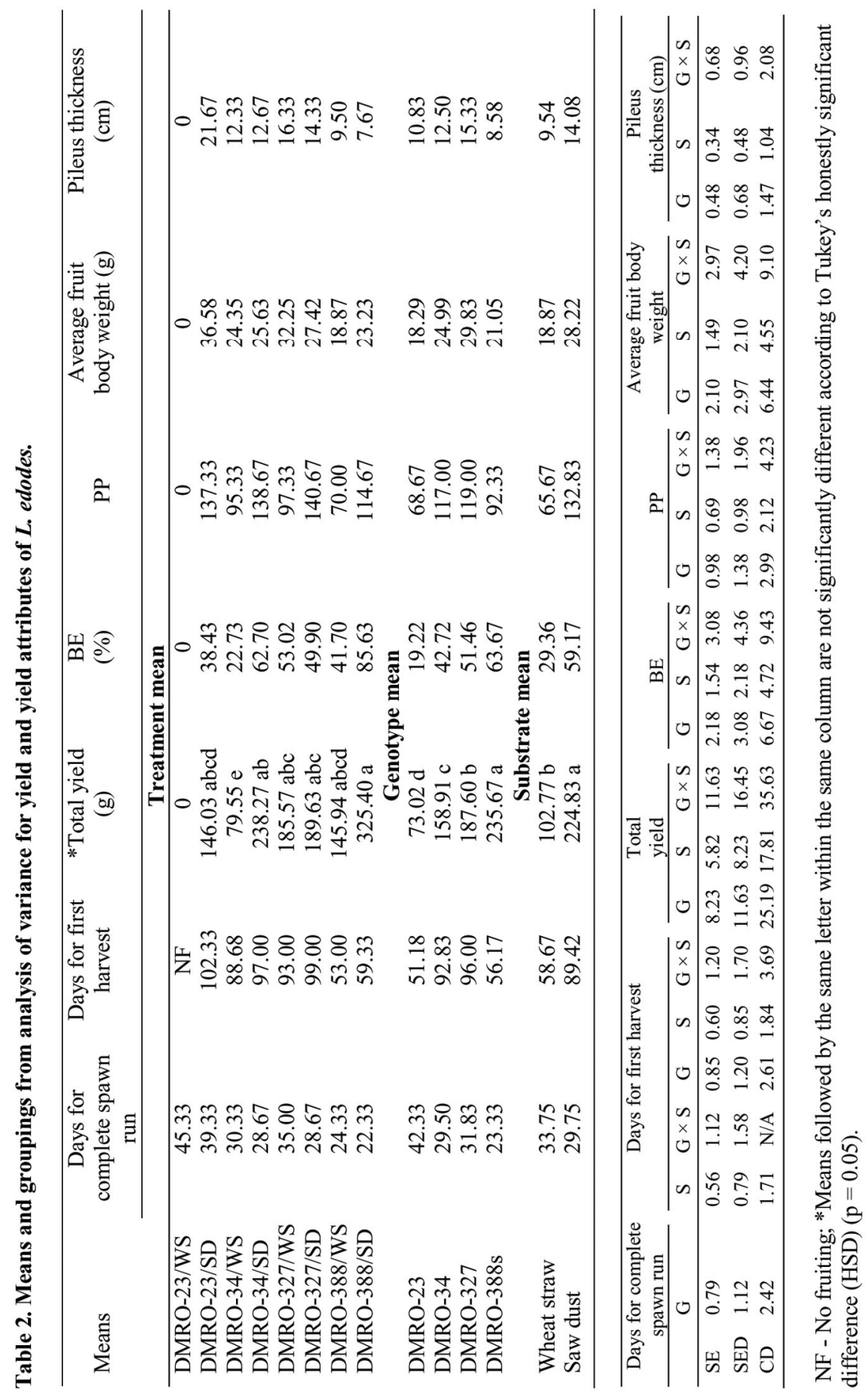


The research thrust on utilization of alternate agro-residues for the cultivation of shiitake is assuming higher significance with passing years. Hence, it is pertinent to study the factors that determine the yield levels of specific genotypes on different substrates. Analysis of $\mathrm{pH}$ of both the substrates at different growth stages represented a similar trend. The $\mathrm{pH}$ decreased steadily from 6.9 to 3.81 till the end of mycelia colonization in WS. Similarly, the pH decreased from 6.7 to 3.74 in SD. This rapid reduction in $\mathrm{pH}$ of the substrate during the colonization phase might act as a prerequisite for primordial initiation (Kalberer 1995). Shiitake mushroom produces the metabolic products and acids which tend to accumulate in the vegetative mycelium. The production of such acids lowers the $\mathrm{pH}$ value of the culture and results in further maturity of the mycelium (Ogha 1999). However, in strain DMRO-23 on WS, the pH remained static at 4.22 after completion of spawn run and there was no further significant reduction in the $\mathrm{pH}$ of the substrate.

In bag log technology, adequate substrate moisture influences the mycelial growth and mushroom production. Ohga (1990) demonstrated that substrate saturated with higher moisture reduced the speed of mycelial colonization by inhibiting the gaseous exchange. Data from the present experiment showed that, spawn run was quicker with a mean average of 29.75 days in SD where the substrate moisture was lesser as $62.4 \%$. In WS, the mean average of 33.75 days was recorded for completion of spawn run at moisture of $65.1 \%$. Shen et al. (2008) reported higher yields and uniform distribution in continuous flushes with less initial moisture compared to the substrate with high initial moisture. Across all the treatments, mushroom yield was higher with uniform distribution in SD where the initial moisture was lesser than the WS.

The resistance of the substrate to biodegradation by fungal strain is attributed to the aromatic and phenolic compounds. In the present study, the total phenolic concentration reduced in WS from 84.6 to $33.39 \mu \mathrm{g} / \mathrm{ml}$ after completion of spawn run in DMRO-327 (Fig. 2). The drastic reduction from control may be attributed to the activity of Mn peroxidise activity that catalyzes the oxidation of phenols to phenoxy radicals (Mata and Savoie 1998). Thereafter, the phenolic concentration increased gradually with each growth stage with variations in different strains.

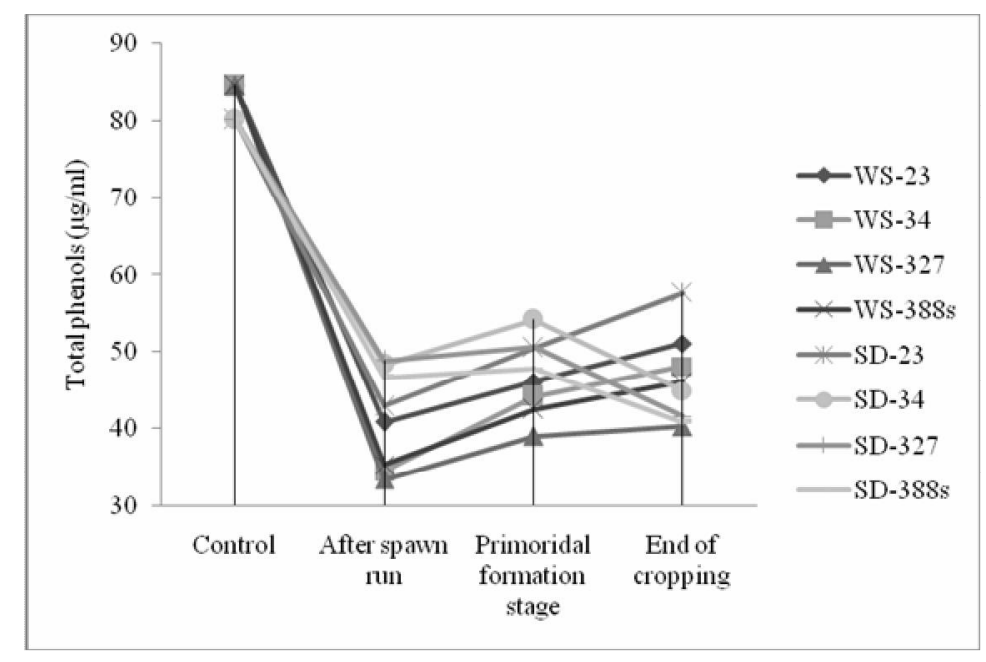

Fig. 2. Variations in total phenol content of WS and SD at different growth stages.

Reduction in total phenols concentration was significant in DMRO-327 which gave highest yield on WS. Increase in total phenolics content at the end of solid state fermentation in WS was earlier reported by Gaitan-Hernandez et al. (2006). Similar trend was observed in SD with strain DMRO- 
23. DMRO-34, 327 and 388s also exhibited the same trend till primordial formation stage and then again decreased at the end of cropping. Plotnikov et al. (2016) reported the activity of Mndependent peroxidase enzyme of $L$. edodes involved in the oxidation and further degradation of lignin. The activity of Mn peroxidase has a similar role in the oxidation of phenolic compounds and is responsible for its variations in the substrate. At the end of cropping, the phenols concentration was lower in SD, a condition possibly due to the higher lignin content of the substrate.

Initial neutral detergent fibre composed of lignin, cellulose and hemicelluloses concentration in WS (70.48\%) and SD (80.65\%) was different. Maximum amount of lignin (23.92\%) and cellulose $(34.72 \%)$ was recorded in SD and hemicellulose content was found highest in WS (28.34\%). Gradual decrease in hemicellulose concentration was recorded in both the substrates at different growth stages with all the genotypes studied (Fig. 3). Hemicellulose is a compound with linear and branched chains of monosaccharides other than glucose with low molecular weight. Hence, it can be easily broken down by the fungal strain and considered as a readily available

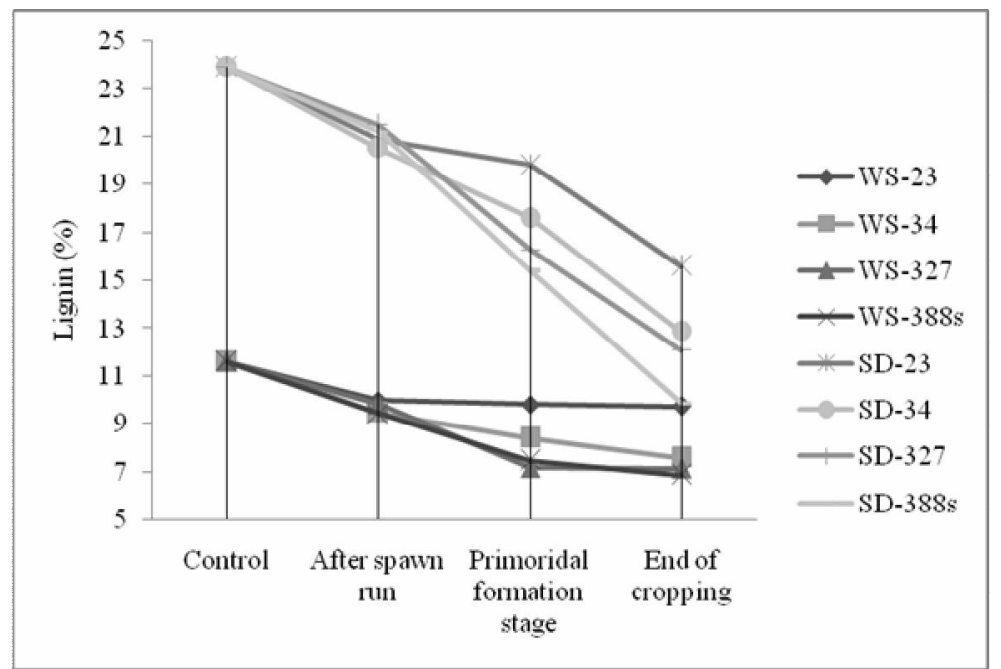

Fig. 3. Variations in hemicellulose content of WS and SD at different growth stages.

source for metabolism prior to the lignin degradation (Philippoussis et al. 2003). The assumption supported the findings of the experiment, where early fruiting was observed in WS with high hemicellulose concentration. Cellulose concentration was found increasing in all the growth stages of the study compared to the initial composition of both the substrates. The per cent of increase in cellulose concentration at spawn run stage was observed higher in WS and specific to strain DMRO-388s (50.82\%) (Fig. 4). At later stages, the concentration was higher in SD specific to DMRO-327 of 48.96 and $48.92 \%$ at primordial formation stage and after cropping, respectively.

The rate of cellulose degradation was lower than the degradation of lignin in both the substrates. Kilpatrick et al. (2000) reported that the availability of cellulose for fungal metabolism will be limited by higher levels of lignin. Being a white rot fungus, L. edodes is tending to decompose lignin for continuing its metabolic life cycle. However, the ability of the fungal strain to depolymerize the cellulose and hemicellulose contents through the extracellular enzymatic system and further yielding of basidiospores depends on the chemical structure of the substrate (Morais et al. 2000). 


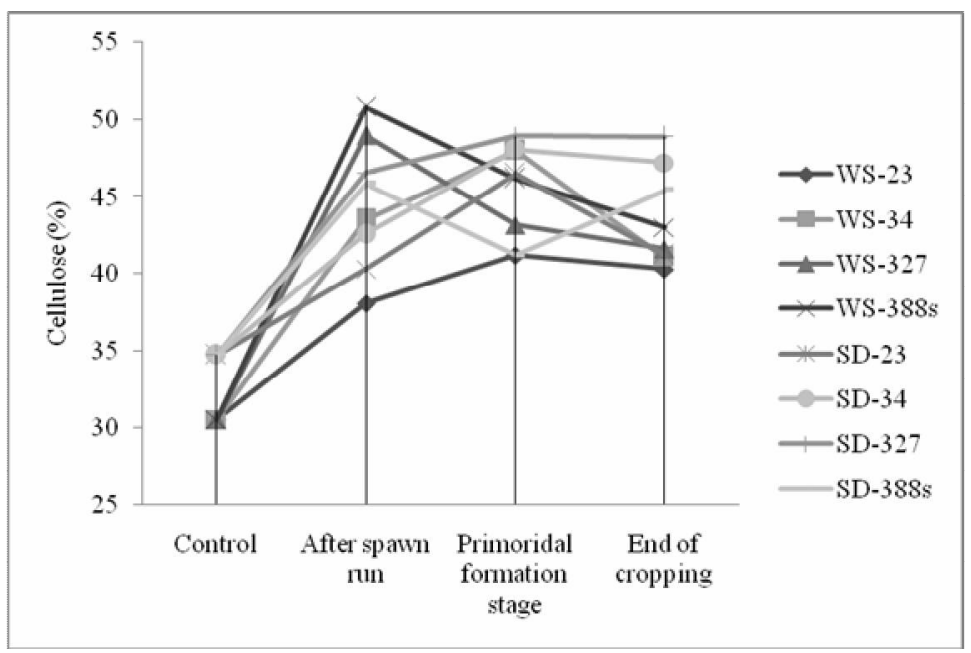

Fig. 4. Variations in cellulose content of WS and SD at different growth stages.

The pattern of lignin degradation was similar in both the substrates by all the strains. The rate of lignin breakdown at the time of primordial initiation and at the end of the crop was highest in strain DMRO-388s on SD attributed its ability to the high BE. The average rate of lignin breakdown was lesser in WS. Among the strains; DMRO-388s showed relatively higher lignin degradation of $40.35 \%$ on WS followed by DMRO-327 of $38.51 \%$ compared to the initial lignin content (Fig. 5). In the present study, lignin degradation ability of the same genotype was found to be varying with the WS and SD substrates. The variability in the lignin degradation capacity influenced by genetic factors of different strains of shiitake was also reported by Blanchette (1991).

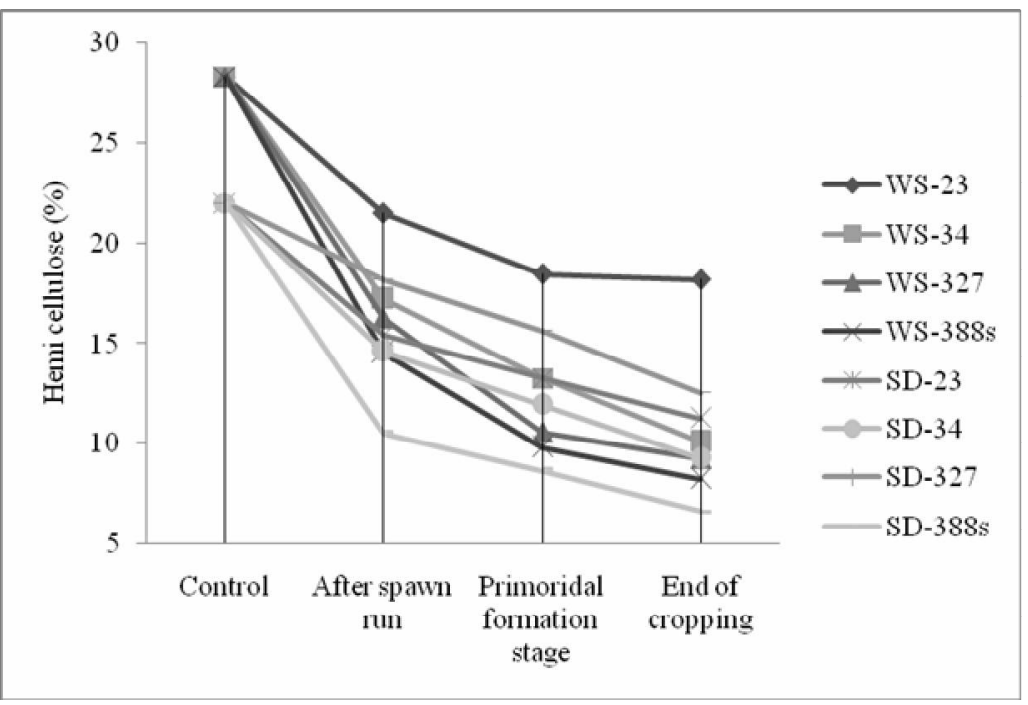

Fig. 5. Variations in lignin content of WS and SD at different growth stages. 
To summarize, the SD has produced a higher yield of $L$. edodes with a longer production period. However, the earliness and higher yield in the first flush in WS opens a new dimension to the commercial cultivation of $L$. edodes. Further advancement in the cultivation of $L$. edodes on WS can bring rich dividends from both an ecological and economic perspective.

\section{References}

Bisen PS, Baghel RK, Sanodiya BS, Thakur GS and Prasad GBKS. 2010. Lentinus edodes: A macrofungus with pharmacological activities. Current Medicinal Chemistry 17: 2419-2430.

Blainski A, Lopes GC and de Mello JC 2013. Application and analysis of the Folin Ciocalteu method for the determination of the total phenolic content from Limonium brasiliense L. Molecules 18: 6852-6865.

Blanchette RA 1991. Delignification by wood-decay fungi. Annual Review of Phytopathology 29: 381-398.

Cochran WG and Cox GM 1957. Experimental Design. 2nd Edition, John Wiley and Sons, New York, 615 p.

Crestini C, Sermanni G and Argyropoulos D 1998. Structural modifications induced during biodegradation of wheat lignin by Lentinula edodes. Bioorganic and Medicinal Chemistry 6: 967-973.

Donoghue JD and Denison WC 1995. Shiitake cultivation: Gas phase during incubation influences productivity. Mycologia 87: 239-244.

Gaitan-Hernandez R, Esqueda M, Guitierrez A and Beltran-Garcia M 2011. Quantitative changes in the biochemical composition of lignocellulosic residues during the vegetative growth of Lentinula edodes. Brazilian Journal of Microbiology 42: 30-40.

Gaitan-Hernandez R, Esqueda M, Gutierrez A, Sanchez A and Beltran-García M 2006. Bioconversion of agro-wastes by Lentinula edodes: The high potential of viticulture residues. Applied Microbiology and Biotechnology 71: 432-439.

Goering HK and Van-Soest PJ 1970. Forage fibre analyses (apparatus, reagents, procedures and some applications, Agricultural Research Service, USDA, Agricultural Handbook No. 379. Washington, D.C.

Kalberer PP 1995. An investigation of the incubation phase of a shiitake (Lentinus edodes) culture. Mushroom Science 14: 375-383.

Kilpatrick M, Murray DJ and Ward F 2000. Influence of substrate formulation and autoclave treatment on Lenitnula edodes production. Mushroom Science 15: 803-810.

Mata G and Savoie JM. 1998. Extracellular enzyme activities in six Lentinula edodes strains during cultivation in wheat straw. World Journal of Microbiology and Biotechnology 14: 513-519

Mata G, Delpech P and Savoie JM 2001. Selection of strains of Lentinula edodes and Lentinula boryana adapted for efficient mycelial growth on wheat straw. Revistalberoamericana de Micologia 18: 118-122.

Morais MH, Ramos AC, Matos N and Santos-Olivera EJ 2000. Production of shiitake mushroom (Lentinula edodes) on lignocellulosic residues. Food Science and Technology International 6: 123-128.

Ohga S 1990. Growth rate of mycelium of shiitake Lentinus edodes, in relation to water potential of medium. Journal of the Faculty of Agriculture, Kyushu University 34: 413-420.

Ogha S 1999. Evaluation of maturity by use of $\mathrm{pH}$ indicators in sawdust-based cultures of Lentinula edodes. Journal of Wood Science 45: 431-434.

Philippoussis A, Diamantopoulou P and Israilides C 2007. Productivity of agricultural residues used for the cultivation of the medicinal fungus Lentinula edodes. International Biodeterioration and Biodegradation 59: 216-219.

Philippoussis AN, Diamantopoulou PA and GI Zervakis 2003. Correlation of the properties of several lignocellulosic substrates to the crop performance of the shiitake mushroom Lentinula edodes. World Journal of Microbiology \& Biotechnology 19: 551-557.

Plotnikov EV, Glukhova LB, Sokolyanskaya LO, Karnachuk OV and Solioz M 2016. Effect of tree species on enzyme secretion by the shiitake medicinal mushroom, Lentinus edodes (Agaricomycetes). International Journal of Medicinal Mushrooms 18(7): 637-644.

Royse DJ, Baars J and Qi T 2017. Current overview of mushroom production in the world. In: Edible and medicinal mushrooms: Technology and applications (Ed. D.C. Zied). New York: John Wiley \& Sons. 
Sharma VP, Annepu SK, Barh A, Shirur M and Kamal S 2018. Genetic divergence and cluster analysis in shiitake genotypes based on yield related traits with commercial breeding significance to shorten the production period. International Journal of Vegetable Science, 1-8.

Sharma VP, Annepu SK, Gautam Y, Singh M and Kamal S 2017. Status of mushroom production in India. Mushroom Research 26(2): 111-120.

Shen Q, Qi T and Royse DJ 2004. Growing Lentinula edodes and other mushrooms in China - A low input technology alternative. Rev. Mex. Micol. 18: 15-20.

Shen Q, Liu P, Wang X and Royse DJ 2008. Effects of substrate moisture content, log weight and filter porosity on shiitake (Lentinula edodes) yield. Bioresource Technology. pp. 8212-8216.

(Manuscript received on 11 June, 2018; revised on 23 September, 2018) 